\title{
Application of the new method of impact hazard assessment and hazard zone division in coal mine
}

\author{
Chengcheng $\mathrm{Li}^{1,2, \text { a }}$ \\ ${ }^{1}$ National Key Laboratory of Gas Disaster Detecting, Preventing and Emergency Controlling, \\ Chongqing 400037, China \\ ${ }^{2}$ Chongqing Research Institute of China Coal Technology \& Engineering Group, Chongqing \\ 400039, China \\ aLCCCHN023@163.com
}

\begin{abstract}
Keywords: Rockburst; comprehensive index method; multi factor coupling; evaluation; risk zoning. Abstract. In order to effectively prevent rockburst, and makes the evaluation and classification of hazardous area of the working face has the potential impact of risk, to put forward the comprehensive index method and the macroscopic evaluation of multi factor coupling impact risk assessment method. In Xinglongzhuang coal mine seven mining area as an example, the use of the method for evaluation and classification of hazardous area, results show that: regional evaluation of rockburst hazard index is 0.65 , has the possibility of rockburst occurring. The multi factors coupling analysis method was developed to delineate the 7 mining working face in the danger zone, so as to provide the scientific basis for the monitoring and prevention of rockburst. The results of the study to prevent rock burst has certain directive significance.
\end{abstract}

\section{Introduction}

Rock burst is one of the most serious natural disasters in coal mine in the world. In our country, most of the coal seams and overlying stratas of the mines have different degrees of impact trend, especially with China's coal mining depth to each year about $20 \mathrm{~m}$ depth increasing, rock burst disaster is becoming more and more serious, has become a major disaster accident control of mine safety production in our country. Therefore, the impact risk assessment and classification of hazardous area, to take timely measures, can effectively reduce the occurrence of disasters. At present, the commonly used method of rock burst evaluation is comprehensive index method ${ }^{[1-4]}$, multi factor coupling method $^{[5-6]}$, numerical simulation method and so on.

\section{Project overview}

Seven mining district in Xinglongzhuang coal mine is located in the southeast corner of the mine, coal measure strata overall to North - East North North West, toward to the southeast East North East of monoclinal structure, stratigraphic dip gently, general 2 to 10 degrees average 7 degrees, the mining area to a depth of more than 600 meters, the mining depth of the largest mining area. The average length of $1290 \mathrm{~m}$ in strike, the average tilt width of $1420 \mathrm{~m}$, an area of about $1.83 \mathrm{Km}^{2}$. Zone faults are well developed, is shown in Table 1, Xiao Jia Zhuang, fault and DF16 fault between by the influence of fault, dip angle of coal seam in about 14 degrees, in the northeast corner of the district local small plant fault traction effect, dip the dada 21 degrees. There is a convex gentlier between three syncline near the DF9 fault, the angle of 2 degrees. 7 District mining engineering plan is shown in Figure 1. 
Table 1 List of fault feature

\begin{tabular}{ccccc}
\hline number & Fault name & nature & dip angle $\left(^{\circ}\right)$ & drop $(\mathrm{m})$ \\
\hline 1 & Xiao Jia Zhuang No. two fault & Normal fault & 70 & $0 \sim 60$ \\
2 & Xiao Jia Zhuang No. three fault & Normal fault & 70 & $0 \sim 40$ \\
3 & Xiao Jia Zhuang No. one fault & Normal fault & 70 & $0 \sim 40$ \\
4 & Xiao chang No.one fault & Normal fault & 70 & $0 \sim 18$ \\
5 & Xiao chang No.two fault & Normal fault & 70 & $0 \sim 28$ \\
6 & DF9 & Normal fault & 70 & $0 \sim 9$ \\
7 & DF16 & Normal fault & 70 & $0 \sim 8$ \\
\hline
\end{tabular}

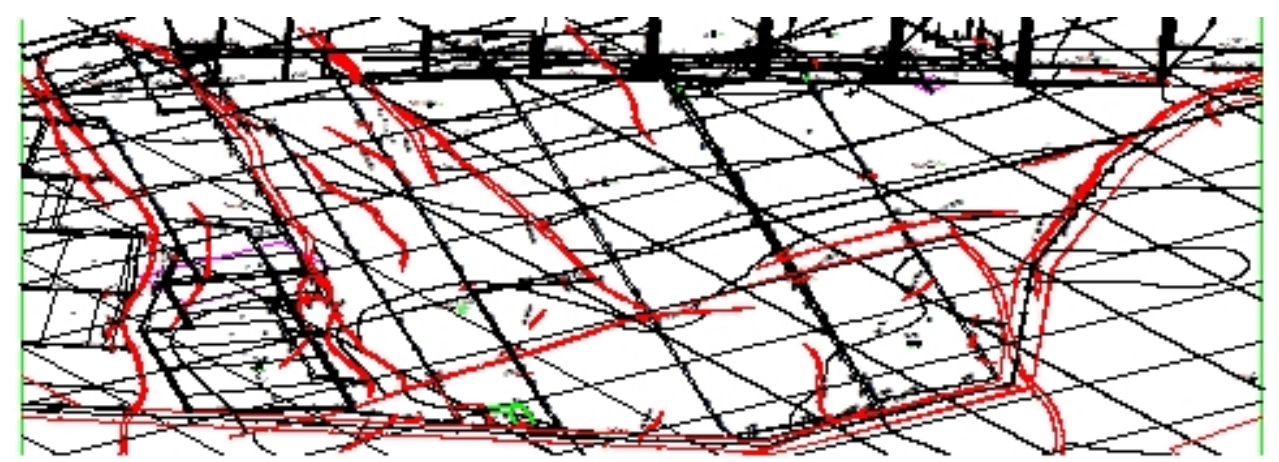

Fig. 1 Mining engineering plane diagram of area seven

\section{Comprehensive index method of impact hazard}

Comprehensive index method is in the foundation of analyzing the variety of rockburst disaster and analysis effects of all the factors of Geology and mining of rock burst, determine the weights of various factors. And then it together and establish a method of rockburst hazard of evaluation model and evaluation and prediction of the impact of risk of.

Impact risk is the risk of rock burst in coal and rock mass. It is not only affected by the mining geological factors, but also affected by the mining conditions. The risk degree of the rock burst can be divided into five levels according to the level of the rock burst dangerous state, as shown in table 2.

Table 2 Jeopardy caused rockburst

\begin{tabular}{cll}
\hline Impact pressure risk grade & Impact pressure dangerous state & Impact pressure risk index \\
\hline A & No danger & $W_{t}<0.3$ \\
B & Weak impact risk & $W_{t}=0.3 \sim 0.5$ \\
C & Medium impact risk & $W_{t}=0.5 \sim 0.75$ \\
D & Strong impact risk & $W_{t}=0.75 \sim 0.95$ \\
E & unsafe & $W_{t}>0.95$ \\
\hline
\end{tabular}

Geological factors and indices affecting the risk of rock burst

The main factors that affect the rock burst are the structure characteristics of the roof and floor rock strata of mining depth and the physical and mechanical properties of coal and the impact tendency.

According to determine the mining working face surrounding geological conditions affect the rock burst risk factors and index of mining working face around the mining geological conditions of rockburst hazard state influence and determine rockburst risk rating index of $W_{\mathrm{t} 1}$.

$$
W_{1}=\frac{\sum_{i=1}^{n_{1}} W}{\sum_{i=1}^{n_{1}} W_{\max }}
$$

$W_{\mathrm{t} 1}$ - Mining geological factors determine the impact pressure risk index;

$W_{\text {imax }}$ - the maximum index value of the numbre i mining geological factors in table 3 ;

$W_{\mathrm{i}}$ - the actual index of the geological factors in the number i mining geology around the site; 
$n_{1}$ - the number of mining geological factors.

Technical factors and index of mining impact on the risk of rock burst

According to the mining technology and mining history, coal pillar, stop production line and the history and technology of mining factors to determine corresponding influence rockburst danger index, so as to provide a basis for rockburst prediction and risk assessment.

According to the mining working face surrounding the mining technical factors of rock burst and the influence degree of index determined around mining working face mining technical factors of rockburst hazard state the influence degree and determining rockburst risk rating index $W_{\mathrm{t} 2}$.

$$
W_{t 2}=\frac{\sum_{i=1}^{n_{12}} W_{i}}{\sum_{i=1}^{n_{2}} W_{i \max }}
$$

$W_{\mathrm{t} 2}$ - Mining technical factors to determine the impact of mining pressure risk index;

$W_{\text {imax }}$ - The maximum value of the index in the technical factors of the number i mining in table 4;

$W_{i}$-Actual risk index of the number i mining technical factors around the Wi mining working face;

$n_{1}$ - The number of mining technology factors.

Prediction and forecast of the degree of rock burst hazard

According to the mining working face surrounding geological factors and mining factors on the rock pressure influence degree and the impact of risk state rating index of $W_{\mathrm{t} 1}$ and $W_{\mathrm{t} 2}$ can determine the mining working face surrounding rock pressure and the comprehensive index $W_{\mathrm{t}}$ of risk rating.

$$
W_{t}=\max \left\{W_{t 1}, W_{t 2}\right\}
$$

$W_{\mathrm{t}}$ was mining working face surrounding rock pressure risk rating index, in order to be able to delineate the rockburst degree.

The impact of risk comprehensive evaluation index of seven mining area

The impact of geological conditions on the impact of the risk index

According to geological conditions of mining area 7, can determine the geological factors of rockburst hazard index, determined by the geological factors of rock pressure risk rating index, as shown in Table 3.

Table 3 Evaluation index of rockburst fixed by geology

\begin{tabular}{cccc}
\hline Number & $\begin{array}{c}\text { Facto } \\
\mathrm{r}\end{array}$ & Influencing factors of dangerous state & $\begin{array}{c}\text { Impact hazard } \\
\text { index }\end{array}$ \\
\hline 1 & $\mathrm{~W}_{1}$ & The coal seam has the impact of rock pressure & 0 \\
2 & $\mathrm{~W}_{2}$ & Mining depth $<700 \mathrm{~m}$ & 1 \\
3 & $\mathrm{~W}_{3}$ & The thick layer of hardroof distance from the coal seam $<50 \mathrm{~m}$ & 3 \\
4 & $\mathrm{~W}_{4}$ & Tectonic stress concentration in the mining area & 2 \\
5 & $\mathrm{~W}_{5}$ & Roof rock stratum thickness characteristic parameter $L_{\mathrm{st}} \geq 50$ & 2 \\
6 & $\mathrm{~W}_{6}$ & Compressive strength of coal $\leq 16 \mathrm{MPa}$ & 0 \\
7 & $\mathrm{~W}_{7}$ & Impact energy index of coal $W_{\mathrm{ET}}<5$ & 2 \\
& & $W_{t 1}=\sum W_{i} / \sum W_{i \max }$ & 0.42 \\
\hline
\end{tabular}

Under the influence of geological factors, the pressure risk index $W_{\mathrm{t} 1}=0.42$, which has weak impact tendency. The main influencing factors are the impact tendency of coal seam, the hard roof rock stratum, the tectonic stress concentration degree caused by the fault.

Impact of mining technology conditions on the impact of the impact of the risk index

7305 working face upper adjacent five mining area of goaf, forming a plurality of mining area of isolated coal pillar, pillar can result in coal and rock mass stress concentration increases the rockburst possibility, 7302 working face is parallel to the working face coal wall of fault exists, and parallel to the fault of mining roadway exist, 7301 working face by the parallel to the working face fault exists, so working face during mining need to design many coal pillar, thereby increasing the working face of the impact of risk the possibility of. The rock burst risk index, which is caused by mining technology conditions, is shown in Table 4. 
Table 4 Evaluation index of rockburst fixed by mining technology

\begin{tabular}{|c|c|c|c|}
\hline Number & $\begin{array}{c}\text { Facto } \\
\mathrm{r}\end{array}$ & Influencing factors of dangerous state & $\begin{array}{l}\text { Impact hazard } \\
\text { index }\end{array}$ \\
\hline 1 & $W_{l}$ & $\begin{array}{l}\text { The vertical distance between the working surface and the residual area or the } \\
\text { stop line }\end{array}$ & 2 \\
\hline 2 & $W_{2}$ & High coal thickness without pressure relief & 3 \\
\hline 3 & $W_{3}$ & On both sides of the gob, length of working face & 2 \\
\hline 4 & $W_{4}$ & The mining face is close to the distance from the mined out area. & 3 \\
\hline 5 & $W_{5}$ & $\begin{array}{l}\text { The mining face is close to the distance of the fault which is larger than } 3 \mathrm{~m} \text {. } \\
\qquad<50 \mathrm{~m}\end{array}$ & 10 \\
\hline \multirow[t]{2}{*}{6} & $W_{6}$ & Goaf treatment method: caving method & 0 \\
\hline & & $W_{t 2}=\sum W_{i} / \sum W_{i \max }$ & 0.65 \\
\hline
\end{tabular}

From the point of view of mining, mining area seven impact hazard index $W_{\mathrm{t} 2}=0.65$, with moderate impact risk.

According to seven mining working face of impulsion pressure state level of risk assessment for medium impact risk and impact of dangerous index $W_{\mathrm{t}}=0.65$, including mining technology influence factor is higher than that of the geological factors.

\section{Multi factor coupling evaluation of the risk of rock burst in working face}

Relationship between coal rock structure and rock burst in working face

7 District No. 3 coal roof is relatively thick powder interbedded sandstone, argillaceous sandstone, siliceous sandstone, thickness were in more than $4 \mathrm{~m}$, the large thickness of even up to $20 \mathrm{~m}$, these all belong to the hard rock, is expected to the strata movement will cause working surface dynamic pressure, should pay special attention to the hard and thick strata fracture caused by dynamic pressure. When the working face mining to roof first caving, or working face mining to "square", these hard rock is rock burst induced by the critical layer.

Engineering analogy evaluation of the relationship between geological structure and rock burst in working face

Geological tectonics is induced rockburst is one of the factors, the 7305 and 7302 working face are parallel working face coal wall of fault and 7305 working face in the fall of DF10 0m 5m, DF16 gap 0m 8m, 7302 DF9 gap 0m 5m. 7301 and 7302 working face are there fault parallel to the roadway, Xiao Jia Zhuang No.2 fault throw 0m 51m, Xiao Jia Zhuang three fault drop 0m 51m. The geological structure the working surface and the mine rockburst occurred the geological structure of the engineering analogy, and then designate the impact danger zone.

Relationship between the spatial structure of overlying strata and rock burst

With the advance of working face, the space structure of overlying strata will gradually form the "O" shape, such as stress concentration, which is likely to cause rock burst.

(1) the first fracture of the old roof

With the working face mining, according to the third chapter and the fourth chapter of the numerical simulation research, experts lots of research and practice, drawn face roof initial fracture appeared about in the working face advance between $40 \sim$, the delineation of the impact risk areas.

(2) working face "square"

When the distance of the working face cut eye 180m, working face into square position, dividing the danger area, the danger zone for $60 \mathrm{~m}$ in front of the working face. The 7301 along the trough in the vicinity of the secondary faults, the square here for high risk area; 7302 working face square, working 
face exactly promote DF9 near the fault, here is a highly dangerous area. Square face, the main roof fracture release energy, impact caused by the high degree of risk, the risk zone for high risk zone.

\section{The impact of seven mining area burst area division}

According to the above the rockburst of multi factor evaluation, combined with numerical simulation results, superposition of dangerous regional location, the degree of risk, these risk areas are divided into two categories, as shown in Figure 2-4, the moderate risk area, shaded segment; high risk areas, grid section.

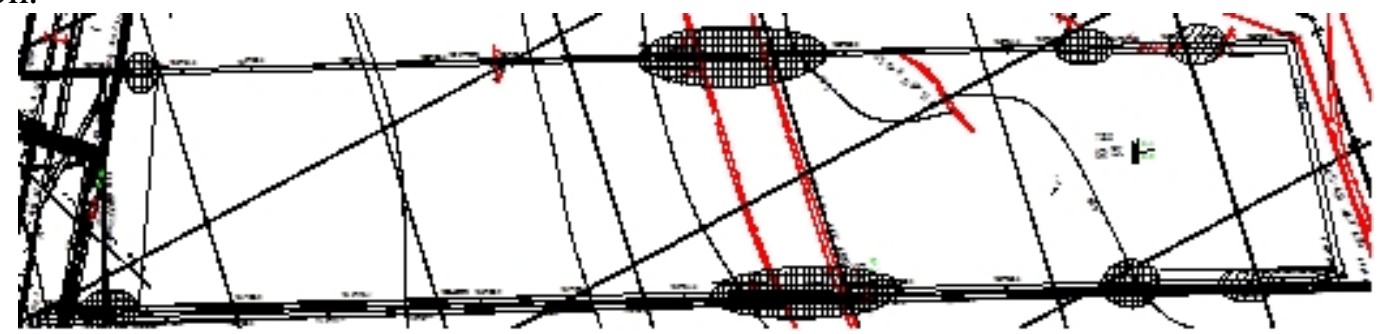

Fig. 2 Impact dangerous zone superposition evaluation using multi-factor of face 7305

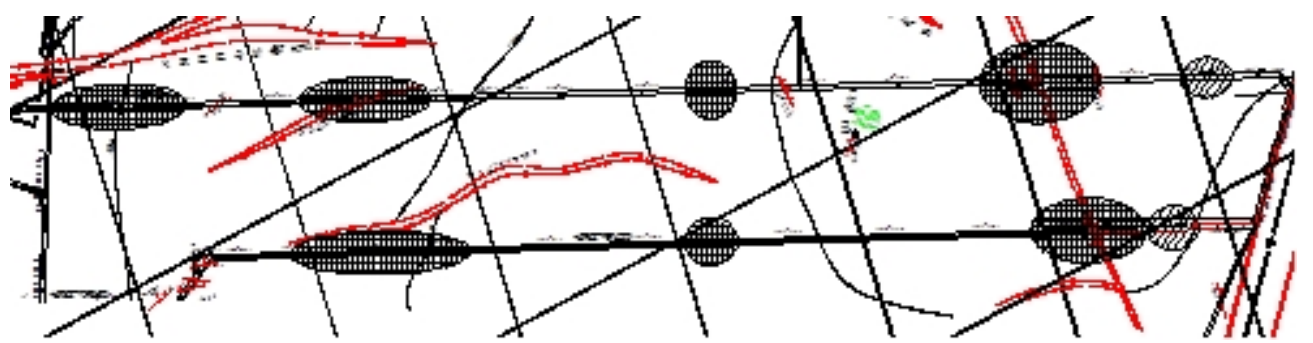

Fig.3 Impact dangerous zone superposition evaluation using multi-factor of face 7302

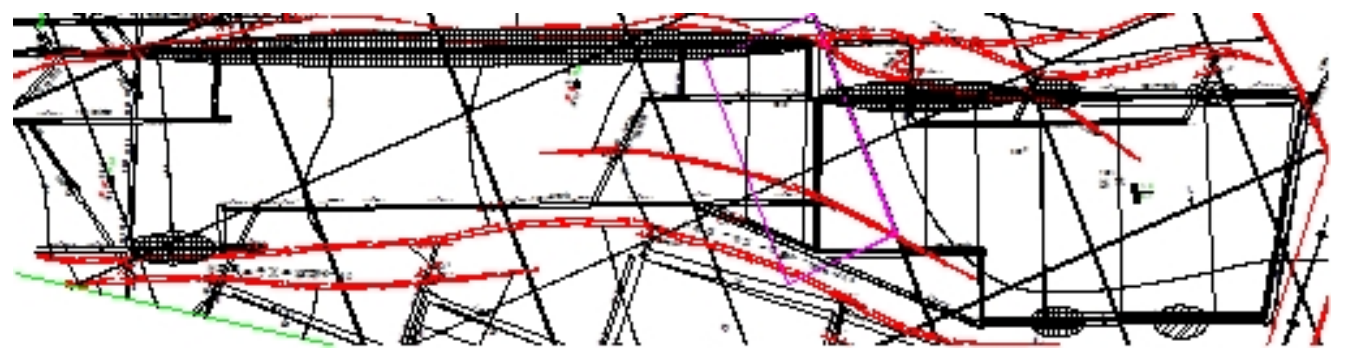

Fig.4 Impact dangerous zone superposition evaluation using multi-factor of face 7301

\section{Engineering application}

\section{Old roof falling}

Working face at the beginning of production, due to the gob span small, old roof stability good, working resistance of support is not, the initial support after the increase in resistance was smaller; when working face roadway propulsion $53.3 \mathrm{~m}$, Xia Xiang promote $6.4 \mathrm{~m}$, the mean propulsive $29.9 \mathrm{~m}$ and workface are more obvious, at the upper part of the working surface roof first weighting arrival, the working face is arranged on the upper part of the first weighting step distance is $51.6 \mathrm{~m}$. The first at the lower working face roof to pressure on the working face roadway advancing to $89 \mathrm{~m}$, Xia Xiang promote $38.2 \mathrm{~m}$ average propulsion $63.6 \mathrm{~m}$, working face is arranged at the lower part of the first weighting step distance is $46.7 \mathrm{~m}$, comprehensive roof first weighting step distance average for $49.15 \mathrm{~m}$. Mine working face pressure behavior is more obvious, mainly for coal wall help increase, support the safety valve opening, increasing the working resistance of support, gob area roof take off the sound, also accompanied by air emission bracket of roof breakage see waste phenomenon. 
Coal body stress meter monitoring

When the working face is in line with $186 \mathrm{~m}$, a set of borehole stress gauge is installed at the side of the working face of the transportation along the groove in the vicinity of the stop line, which is used to monitor the stress state of the coal body before and after the stop of the working face.

According to the stress of coal working face along the strike of the stress distribution characteristic analysis, borehole stress meter installation, in the range of leading face $80 \sim 180 \mathrm{~m}$, as far away from the working face, the steady state stress gauge to maintain the initial stress in advance; working face in the range of $80 \sim 30 \mathrm{~m}$, with a working face gradually advance stress meter slowly compression stress gradually increased; in advancing working range of $30 \sim 20 \mathrm{~m}$, advance support stress influence of mining working face, stress sharp pressure, stress increases rapidly, the coal body elasticity, compressive ability; in the leading face stress range $20 \sim 15 \mathrm{~m}$ meter peak coal compressive strength at this time reached the limit, beginning with the cracks increase after fracture; stress gradually releasing stress, see figure 5 .

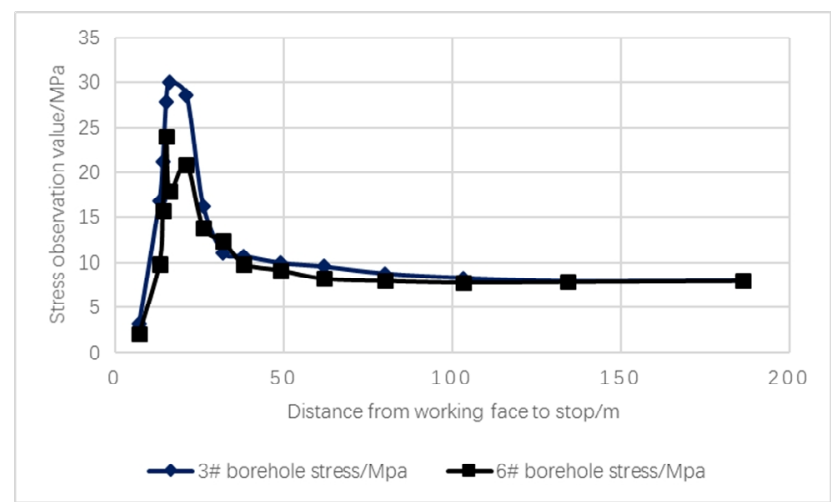

Fig.5 Stress distribution characteristics of coal along the face toward

\section{Conclusions}

(1) using the comprehensive index method to evaluate the impact hazard of seven mining area: geological factors of ore pressure risk index $W_{\mathrm{t} 1}=0.42$, has a weak impact trend of. Main factors affecting coal seam rockburst tendency, hard roof rock strata and faults caused by tectonic stress concentration degree; mining technological conditions influencing factors, 7 mining shock hazard index $W_{\mathrm{t} 2}=0.65$ with medium impact risk. According to 7 mining working face of impulsion pressure state level of risk assessment for medium impact risk and impact of dangerous index $W_{\mathrm{t}}=0.65$, including mining technology influence factor is higher than that of the geological factors.

(2) using the multi factor coupling evaluation method of coal rock structure, geological structure, spatial structure of overlying strata and coal pillar induced rockburst was evaluated, and out of the dangerous area.7305 working surface a total of six high risk area, two moderate risk zone; 7301 working face total five high risk area, two moderate risk zone; 7302 working face total seven high risk area, two moderate risk area.

\section{Acknowledgements}

This work was financially supported by the The science and technology innovation fund of China coal science and Industry Group Co. Ltd. (2014QN002).

\section{References}

[1] DOU Linming, HE Xueqiu. Theory and technology of rock burst prevention[M]. Xuzhou : China University of Mining and Technology Press , 2001 : 124-133. ( In Chinese )

[2] YU Zhengxing, JIANG Fuxing , GUI Bing. Mining Safety and Environmental Protection , 2011 , 38(5) : 30-32. ( In Chinese ) 
[3] ZHANG Zhizhen, GAO Feng , XU Aibin , et al. Journal of China University of Mining and Technology , $2011,40(3):$ 379-384. ( In Chinese )

[4] LIU Xiaofei , WANG Enyuan, ZHAO Enlai , et al . Journal of Mining \& Safety Engineering , 2010 , 27( 2) : 215-218 . ( In Chinese )

[5] FENG Yi , LIU Tong, YIN Zeng, SHI Fu . Safety in Coal Mines,2013,44(8):196-199. ( In Chinese )

[6] Goszcz, Antoni . Archiwum Gornictwa , 1991,36(3):239-261 . 